\title{
Communities of Practice for Functional Learning in Agile Contexts: Definition Approach and Call for Research
}

\author{
https://doi.org/10.3991/ijac.v14i1.21939 \\ Atilla Wohllebe ( $\left.{ }^{\varpi}\right)$, Michael Götz \\ MATE Hungarian University of Agriculture and Life Sciences, Kaposvár, Hungary \\ atilla.wohllebe@gmail.com
}

\begin{abstract}
With the increasing relevance of information technology and software development in particular, the popularity of agile working methods like Scrum and Kanban has grown significantly in recent years. Characteristic for many agile frameworks like Scrum is the work in cross-functional teams. While this has many advantages in development, cross-functional teams make functional learning very challenging. Therefore, so-called Communities of Practice (CoPs) have been established in practice. This paper defines CoPs in the agile context and reviews existing literature on CoPs in agile context. There is very little literature on how CoPs in the agile context are employed to enhance functional learning. For example, the author calls for more scientific research on CoPs' success factors and contribution to functional learning outcomes in agile environments.
\end{abstract}

Keywords - Community of practice, agile, scrum, cross-functional teams, organizational learning

\section{Introduction}

Increasing digitalization and the associated growing relevance of information technology are leading to major challenges in many industries [1]-[5]. Characteristic of this is a high level of dynamism with rapid changes, increased requirements and the unpredictability of future developments [6]. To meet the challenges of digitalization, working according to agile methods has proven its worth [7]. The methods are particularly suitable for dynamic competitive and market environments and go hand in hand with a comprehensive change in the leadership culture in companies [8], [9]. Accordingly, the spread of agile working methods has increased significantly in recent years.

Agile working methods such as Scrum or Kanban are particularly well suited to developing products and solutions quickly and flexibly in a customer- and targetoriented manner [10]. Against the background of the central importance of customer satisfaction, it is also particularly worth mentioning that agile methods are especially suitable for creating added value for customers [11]-[14]. In addition, the quality of software development also improves [15], [16]. The basis of agile working methods is the agile manifesto [17]. Feedback and transparency can be identified as core features [18]. 
In parallel, digitalization with its dynamics also places new demands on learning faster learning in particular is required [19]. It serves to develop skills with the aim of improving performance [20]. Learning is not only important at the individual level, but also for organizations as a whole, since learning organizations also perform better, as the literature repeatedly shows [21]-[23]. Analogous to the learning organization, organizational learning describes the ability to draw conclusions from past experiences for action in the present [24]. It is a process of continuous improvement through knowledge and oversight [25]. In the context of the agile working method Scrum, learning within the cross-functional team leads to improvement when going through the Scrum process [26]. This is especially ensured by retros [27], [28].

At the same time, however, there are no explicit instructions or meeting formats in Scrum to enable functional learning [29]. Functional learning is understood as the acquisition of knowledge with the aim of improving the skills required to perform a specific (professional) function (e.g. "front-end development", "user experience design", "marketing", "key account management"). In companies, CoPs which are already known in other contexts have become established for this purpose [26]. These CoPs have also long been prevalent outside of agile working methods and functional learning [30]. First emerging in the early 1990s, CoPs in the broadest sense are a practice-based community of individuals who work on similar tasks and therefore want to learn from each other [31].

So far, little research has been done on CoPs in the agile context. A few research papers (including [32], [33]) deal with CoPs in agile transformation processes. However, only little knowledge exists on how CoPs in the agile context contribute to functional learning [34]-[36].

This paper first provides an introductory overview of the existing CoP literature in general. Subsequently, selected works on CoPs in the agile context are considered. On this basis, a definitional approach to CoPs in the agile context is provided. This is followed by a call for more scholarly attention to the role of CoPs as a tool for functional learning in agile work environments.

\section{$2 \quad$ Literature Review}

First, consideration is given to basic literature on CoPs.

Lave \& Wenger laid the foundation for the concept of community of practice in 1991. For the first time, the authors understand learning in the context of social relationships. Accordingly, learning requires not only structures and models, but also a form of community. Thus, the concept of Community of Practice was created [31].

Characteristic for a $\mathrm{CoP}$ is a common topic of the community as a meaningful element or as a reason to come together in the first place. The community is thereby characterized by the interaction of the participants with each other and the willingness to share individual knowledge [37]. In this respect, a CoP can be understood as a group of experts who share an interest or topic and want to deepen their knowledge in this regard [38]. 
The need for such a CoP arises primarily from the existence of implicit, tacit knowledge. Since this is difficult to document formally, it can preferably be distributed via informal exchange [39]. Accordingly, in learning scientific skills, for example, CoPs encourage solicitation of feedback and continuous progress [40].

CoPs enable the exchange of information among similarly thinking people from related or identical functions. This circumstance gives people the feeling that they can develop their function independently [41]. This is why CoPs lead, among other things, to faster training of new employees, to faster adaptation to customer needs, to a reduction in rework and to new ideas for products and services [42]. The distribution of knowledge also ensures less dependence on individuals and keeps knowledge constantly up to date; a very important advantage, especially in dynamic environments [43].

For a CoP to be sustainable, the community must accept constant change and be open to dialog with internal and external perspectives. Actively inviting external people for new impulses, high quality standards and regular meetings also contribute to the continuity of a CoP [37]. In-person meetings also promote community building, idea sharing, and relationship building among individual members [41]. Some authors also emphasize a high degree of ability to self-organize among the participants and teams involved [39]. Others, however, emphasize that a formal leader can also be beneficial to the learning process [41].

Other sources explain that CoPs can also be cross-organizational and foster knowledge and creativity [44]. Furthermore, CoPs can take place virtually and provide remote or isolated areas with the opportunity to acquire knowledge and learn [45].

The following is a review of the little literature on CoPs that explicitly relates to agile contexts.

In the context of large-scale agile transformations, a systematic review of relevant research shows that CoPs (along with other practices such as coaching, piloting, and continuous integration) have been less of a focus of research to date. In particular, research on agile transformations focuses instead on success factors, challenges, and reasons for the intended transformation. Research also shows that agile communities in a broader sense have a positive impact on the success of transformation projects [46].

Furthermore, when applying agile working methods, CoPs can lead to better products being developed and new ideas for products being generated more effectively. A high degree of autonomy is important for the success of a CoP, whereby it is recommended that managers monitor the activities and, if necessary, have a controlling function [47].

In the context of organizational learning in the application of Scrum, it can also be shown that CoPs serve as networks in the sense of the four elements of organizational learning. They are thus, despite their not necessarily formal character, part of a defined learning structure. The CoP is identified as a central element for functional learning in organizations consisting of cross-functional teams [26].

Perhaps the most significant contribution to CoPs in the agile context is made by a large-scale case study at Ericsson. As part of a transformation, a company is to 
become a lean and agile organization. Four hundred employees in 40 Scrum teams at three locations are studied in 52 semi-structured interviews and through observation over two years. CoPs are established and run for different purposes, including knowledge sharing and learning, coordination and organizational development. Success factors identified include a good topic, the presence of a leader, meetings with a clear agenda, decision-making authority, an open community, supportive tools, and regular meetings [38].

These are the few findings that are known about CoPs in the agile context and especially against the background of functional learning.

\section{Definition Approach}

The term "community of practice" has been known for many years and has been described and defined in a similar way several times. Essential characteristics are learning [31], [38] in a community [31] on a common topic [37], [38] with a defined purpose for the acquired knowledge [38].

In the context of learning in organizations, CoPs are also described as requiring self-organization [39]. CoPs take place either in-person [41] or virtually [45] with some regularity [38]. In organizations with cross-functional teams, they contribute to functional learning at the individual and organizational levels [26].

Consequently, community of practice in the agile context is defined as follows:

In the agile context, a community of practice is defined as the-usually regularly occurring - meeting (in-person or virtually) of people of the same function from different cross-functional teams with the goal of sharing functional knowledge and experiences to improve within their function.

This definition is the first definitional approach that combines the previously generic concept of CoP with cross-functional teams, which are characteristic of agile working methods, and relates it specifically to functional learning.

\section{Summary and Conclusion}

The goal of this position paper was to understand CoPs for functional learning in agile work environments. For this purpose, the corresponding existing literature was considered. After the initial review of basic literature on CoPs, selected previous findings on CoPs in the agile context were highlighted. In summary, there is little practical literature in this area to date.

In addition, the definition of classical CoPs was extended to CoPs in the agile context with the goal of functional learning.

In summary, it must be stated that there is still far too little knowledge in this context. In many companies, CoPs are now a natural part of agile transformation processes and serve to exchange functional knowledge among participants who come from different cross-functional teams. In science, these application scenarios seem to have 
received little attention so far. This paper is therefore also a call to researchers in the field of management and organization to take a closer look at CoPs. In particular, research that provides insights into how CoPs contribute to functional learning, what the success factors are, and what the learning success of individual members and the organization as a whole depends on is needed.

\section{$5 \quad$ References}

[1] R. Deckert and A. Wohllebe, Digitalisierung und Einzelhandel: Taktiken und Technologien, Praxisbeispiele und Herausforderungen, 1st ed. Wiesbaden, Germany: Springer Gabler, 2021. https://doi.org/10.1007/978-3-658-33090-3 5

[2] E. Diez, "Managing A Veterinary Practice: A Guide To Organizational Culture In Veterinary Practice," IJARBM, vol. 1, no. 1, pp. 18-26, Dec. 2020, https://doi.org/10.51137 /ijarbm.2020.1.1.2

[3] R. Filieri, S. Alguezaui, and F. McLeay, "Why do travelers trust TripAdvisor? Antecedents of trust towards consumer-generated media and its influence on recommendation adoption and word of mouth," Tourism Management, vol. 51, pp. 174-185, Dec. 2015, https://doi.org/10.1016/j.tourman.2015.05.007

[4] S. Papadakis, M. Kalogiannakis, and N. Zaranis, "Educational apps from the Android Google Play for Greek preschoolers: A systematic review," Computers \& Education, vol. 116, pp. 139-160, Jan. 2018, https://doi.org/10.1016/j.compedu.2017.09.007.

[5] F. Ross, "Hearing Aid Accompanying Smartphone Apps in Hearing Healthcare. A Systematic Review," Applied Medical Informatics, vol. 42, no. 4, Nov. 2020, [Online]. Available: https://ami.info.umfcluj.ro/index.php/AMI/article/view/792

[6] A. Fielitz and C. Hug, "Agile Leadership - An Online-Based Advanced Training Programme for Leaders Including Personal (online) Coaching Sessions," International Journal of Advanced Corporate Learning (iJAC), vol. 12, no. 2, Art. no. 2, Nov. 2019, Accessed: Feb. 01, 2021. [Online]. Available: https://online-journals.org/index.php/ijac/article/view/11382 . https://doi.org/10.3991/ijac.v12i2.11382

[7] F. Salvetti and B. Bertagni, "Leadership 5.0: An Agile Mindset for a Digital Future," International Journal of Advanced Corporate Learning (iJAC), vol. 13, no. 2, Art. no. 2, Sep. 2020, Accessed: Feb. 01, 2021. [Online]. Available: https://onlinejournals.org/index.php/i-jac/article/view/17033. https://doi.org/10.3991/ijac.v13i2.17033

[8] J. C. Arimie and A. O. Oronsaye, "Assessing Employee Relations and Organizational Performance: A Literature Review," IJARBM, vol. 1, no. 1, pp. 1-17, Dec. 2020, https://doi.org/10.51137/ijarbm.2020.1.1.1

[9] K. T. Stormi, T. Laine, and T. Korhonen, "Agile performance measurement system development: an answer to the need for adaptability?" J Acc \& Organizational Change, vol. 15, no. 2, pp. 231-256, Jun. 2019, https://doi.org/10.1108/JAOC-09-2017-0076

[10] S. Alsaqqa, S. Sawalha, and H. Abdel-Nabi, "Agile Software Development: Methodologies and Trends," International Journal of Interactive Mobile Technologies (iJIM), vol. 14, no. 11, Art. no. 11, Jul. 2020, Accessed: Feb. 01, 2021. [Online]. Available: https://onlinejournals.org/index.php/i-jim/article/view/13269.https://doi.org/10.3991/ijim.v14i11.13269

[11] S. Denning, "Lessons learned from mapping successful and unsuccessful Agile transformation journeys," SL, vol. 47, no. 4, pp. 3-11, Jul. 2019, https://doi.org/10.1108/SL-042019-0052

[12] S. Y. Lam, V. Shankar, M. K. Erramilli, and B. Murthy, "Customer Value, Satisfaction, Loyalty, and Switching Costs: An Illustration From a Business-to-Business Service Con- 
text," j acad market sci, vol. 32, no. 3, pp. 293-311, Jul. 2004, https://doi.org/10.1177 /0092070304263330

[13] A. Wohllebe, F. Ross, and S. Podruzsik, "Influence of the Net Promoter Score of Retailers on the Willingness of Consumers to Install Their Mobile App," Int. J. Interact. Mob. Technol., vol. 14, no. 19, 2020, https://doi.org/10.3991/ijim.v14i19.17027

[14] C. Xu, D. Peak, and V. Prybutok, "A customer value, satisfaction, and loyalty perspective of mobile application recommendations," Decision Support Systems, vol. 79, pp. 171-183, Nov. 2015, https://doi.org/10.1016/j.dss.2015.08.008

[15] G. Arcos-Medina and D. Mauricio, "The Influence of the Application of Agile Practices in Software Quality Based on ISO/IEC 25010 Standard:” International Journal of Information Technologies and Systems Approach, vol. 13, no. 2, pp. 27-53, Jul. 2020, https://doi.org/10.4018/IJITSA.2020070102

[16] K. E. Kendall, S. Kong, and J. E. Kendall, "The Impact of Agile Methodologies on the Quality of Information Systems: Factors Shaping Strategic Adoption of Agile Practices," International Journal of Strategic Decision Sciences, vol. 1, no. 1, pp. 41-56, Jan. 2010, https://doi.org/10.4018/jsds.2010103003.https://doi.org/10.4018/978-1-4666-1589-2.ch012

[17] K. Beck, M. Beedle, A. van Bennekum, A. Cockburn, and W. Cunningham, "Manifesto for Agile Software Development," Manifesto for Agile Software Development, 2001. https://agilemanifesto.org/ (accessed Jul. 19, 2020).

[18] R. Lethmate, "Auf einen Kaffee mit Ralf Lethmate," 2016.

[19] F. Babic and V. Gaspar, "The Creative Ecosystem to Improve the Students Adaptation to Current Trends in IT Companies," in Teaching and Learning in a Digital World: Proceedings of the 20th International Conference on Interactive Collaborative Learning, Dec. 2017, https://doi.org/10.1007/978-3-319-73210-7

[20] D. Guralnick, "Putting the Education into Educational Simulations: Pedagogical Structures, Guidance and Feedback," International Journal of Advanced Corporate Learning (iJAC), vol. 2, no. 1, pp. 10-15, Feb. 2009, Accessed: Feb. 01, 2021. [Online]. Available: https://www.learntechlib.org/p/45592/ . https://doi.org/10.3991/ijac.v2i1.693

[21] S. Ali, L. D. Peters, I. U. Khan, W. Ali, and N. Saif, "Organizational Learning and Hotel Performance: The Role of Capabilities' Hierarchy," International Journal of Hospitality Management, vol. 85, p. 102349, Feb. 2020, https://doi.org/10.1016/j.ijhm.2019.102349

[22] I. M. Gachanja, S. I. Nga'nga', and L. M. Kiganane, "Influence of organization learning on innovation output in manufacturing firms in Kenya," International Journal of Innovation Studies, vol. 4, no. 1, pp. 16-26, Mar. 2020, https://doi.org/10.1016/j.ijis.2020.02.001

[23] M. R. J. Qureshi and M. Kashif, "Seamless long-term learning in agile teams for sustainable leadership," in 2009 International Conference on Emerging Technologies, Islamabad, Pakistan, Oct. 2009, pp. 389-394, https://doi.org/10.1109/ICET.2009.5353140

[24] B. Levitt and J. G. March, "Organizational Learning," Annual Review of Sociology, vol. 14, pp. 319-340, 1988, Accessed: Jul. 22, 2020. [Online]. Available: https://www.jstor.org /stable/2083321

[25] C. M. Fiol and M. A. Lyles, "Organizational Learning," The Academy of Management Review, vol. 10, no. 4, pp. 803-813, 1985, https://doi.org/10.2307/258048 https://doi.org/10.5465/amr.1985.4279103

[26] A. Wohllebe, "Scrum as an Agile Method for Strategic Organizational Learning in Digital Enterprise Transformation: Applying the Four Elements of Organizational Learning," in Disruptive Technology and Digital Transformation for Business and Government, K. Sandhu, Ed. Hershey, PA: IGI Global, 2021, pp. 24-42. https://doi.org/10.4018/978-17998-8583-2.ch002 
[27] E. Derby and D. Larsen, Agile retrospectives: making good teams great. Raleigh, NC: Pragmatic Bookshelf, 2006.

[28] P. K. Gaikwad, C. T. Jayakumar, E. Tilve, N. Bohra, W. Yu, and M. Spichkova, "Voiceactivated solutions for agile retrospective sessions," Procedia Computer Science, vol. 159, pp. 2414-2423, Jan. 2019, https://doi.org/10.1016/j.procs.2019.09.416

[29] M. C. Annosi, A. Martini, F. Brunetta, and L. Marchegiani, "Learning in an agile setting: A multilevel research study on the evolution of organizational routines," Journal of Business Research, vol. 110, pp. 554-566, Mar. 2020, https://doi.org/10.1016 /j.jbusres.2018.05.011

[30] R. McDermott and D. Archibald, "Harnessing Your Staff's Informal Networks," Harvard Business Review, Mar. 01, 2010.

[31] J. Lave and E. Wenger, Situated learning: legitimate peripheral participation. Cambridge [England]; New York: Cambridge University Press, 1991. https://doi.org/10.1017 /cbo9780511815355

[32] T. Kahkonen, "Agile methods for large organizations - building communities of practice," in Agile Development Conference, Jun. 2004, pp. 2-10, https://doi.org/10.1109 /ADEVC.2004.4

[33] M. Paasivaara and C. Lassenius, "Deepening Our Understanding of Communities of Practice in Large-Scale Agile Development," in 2014 Agile Conference, Jul. 2014, pp. 37-40, https://doi.org/10.1109/AGILE.2014.18

[34] Google Scholar, “"communities of practice agile' - Search Results,” Google Scholar, 2021. https://scholar.google.com/scholar?hl=de\&as sdt=0\%2C $5 \& q=$ communities + of + practice + a gile\&btnG $=($ accessed Feb. 03, 2021). https://doi.org/10.15845/noril.v1i1.10.s3

[35] ResearchGate, “community of practice agile' - ResearchGate," ResearchGate, 2021. https://www.researchgate.net/search.Search.html?type=publication\&query=community $\% 2$ 0of\%20practice\%20agile (accessed Feb. 01, 2021). https://doi.org/10.4016/9522.01

[36] ScienceDirect, “"community of practice agile' - ScienceDirect," ScienceDirect, 2021. https://www.sciencedirect.com/search?qs=community\%20of\%20practice\%20agile (accessed Feb. 01, 2021). https://doi.org/10.1002/leap.1142

[37] E. Wenger, R. A. McDermott, and W. Snyder, Cultivating Communities of Practice: A Guide to Managing Knowledge. Boston, Mass: Harvard Business Review Press, 2002.

[38] M. Paasivaara and C. Lassenius, "Communities of practice in a large distributed agile software development organization - Case Ericsson," Information and Software Technology, vol. 56, no. 12, pp. 1556-1577, Dec. 2014, https://doi.org/10.1016/j.infsof.2014.06.008

[39] T. Chau and F. Maurer, "Tool Support for Inter-team Learning in Agile Software Organizations," in Advances in Learning Software Organizations, vol. 3096, G. Melnik and H. Holz, Eds. Berlin, Heidelberg: Springer Berlin Heidelberg, 2004, pp. 98-109. https://doi.org/10.1007/978-3-540-25983-1 10

[40] H. Zhang, M. W. Easterday, E. M. Gerber, D. Rees Lewis, and L. Maliakal, “Agile Research Studios: Orchestrating Communities of Practice to Advance Research Training," in Proceedings of the 2017 ACM Conference on Computer Supported Cooperative Work and Social Computing, New York, NY, USA, Feb. 2017, pp. 220-232, https://doi.org/10.1145/2998181.2998199

[41] K.S. Milway and . A Saxton, "The Challenge of Organizational Learning," Stanford Social Innovation Review 2011, Review, 2011 https://ssir.org/articles/entry/ the challenge of_organizational_learning (accessed Jul. 19, 2020)

[42] E. L. Lesser and J. Storck, "Communities of practice and organizational performance," IBM Syst. J., vol. 40, no. 4, pp. 831-841, 2001, https://doi.org/10.1147/sj.404.0831 
[43] V. Santos, A. Goldman, A. C. M. Shinoda, and A. L. Fisher, "A view towards Organizational Learning: An empirical study on Scrum implementation," in Proceedings of the 23rd International Conference on Software Engineering \& Knowledge Engineering, Miami Beach, USA, 2011, pp. 583-589, Accessed: Jul. 19, 2020. [Online]. Available: https://www.researchgate.net/publication/221391284 A view towards Organizational Le arning An empirical study on Scrum implementation

[44] A. Mavri, A. Ioannou, and F. Loizides, "Design students meet industry players: feedback and creativity in communities of practice," The Internet and Higher Education, p. 100792, Jan. 2021, https://doi.org/10.1016/j.iheduc.2021.100792

[45] R. Abiodun, F. Daniels, D. C. Pimmer, and J. Chipps, "A whatsapp community of practice to support new graduate nurses in South Africa," Nurse Education in Practice, vol. 46, p. 102826, Jul. 2020, https://doi.org/10.1016/j.nepr.2020.102826

[46] K. Dikert, M. Paasivaara, and C. Lassenius, "Challenges and success factors for large-scale agile transformations: A systematic literature review," Journal of Systems and Software, vol. 119, pp. 87-108, Sep. 2016, https://doi.org/10.1016/j.jss.2016.06.013 .

[47] S. Borzillo, A. Schmitt, and M. Antino, "Communities of practice: keeping the company agile," Journal of Business Strategy, vol. 33, no. 6, pp. 22-30, Jan. 2012, https://doi.org/10.1108/02756661211281480

\section{Authors}

Atilla Wohllebe is currently a Ph.D. student at MATE Hungarian University of Agriculture and Life Sciences - Kaposvár Campus, Kaposvár, Hungary. His research topics include mobile apps \& digital marketing, e-commerce \& retail, and agile working methods. He holds a M.Sc. in E-Commerce from Wedel University of Applied Science, Germany. Working in stationary retail and e-commerce, he advises companies on how to meet the challenges of digitalization both strategically and technologically.

Michael Götz is currently a Ph.D. student at MATE Hungarian University of Agriculture and Life Sciences - Kaposvár Campus, Kaposvár, Hungary. His research topics include agile working, agile and low-hierarchy organizations, and the transformation to agile organizational forms and their impact on employees and management. He holds his Diploma in Economics and his M.A. in Political Science, Macroeconomics and Psychology from the University of Augsburg, Germany. He advises industry and government on how best to meet the challenges of moving towards agile ways of working and agile organizational forms. m.w.goetz@,web.de

Article submitted 2021-02-10. Resubmitted 2021-04-28. Final acceptance 2021-04-28. Final version published as submitted by the authors. 